\title{
Meta Analisis Pengaruh Model Pembelajaran POE Terhadap Pemahaman Konsep
}

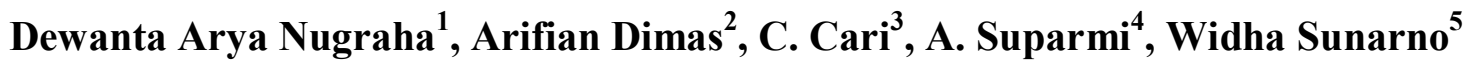 \\ ${ }^{1,5}$ Doktor Pendidikan IPA, FKIP, Universitas Sebelas Maret, Indonesia \\ ${ }^{2}$ Program Studi Pendidikan IPA STKIP Modern Ngawi, Indonesia \\ ${ }^{3,4}$ Fisika, Universitas Sebelas Maret, Indonesia
}

Email: dewanta.an@student.uns.ac.id / dewanta.an@gmail.com

\begin{abstract}
This study aims to analyze the POE learning model for understanding physics concepts. The method used in this research is a meta-analysis. Meta-analysis is research that examines the results of similar studies. Data obtained from national and international journal documents taken by purposive sampling based on conformity with the research theme. Data analysis using quantitative data analysis with presentations and qualitative data analysis in the form of descriptions of research results found. Based on data analysis, it found that the POE learning model can improve students' understanding of concepts.
\end{abstract}

Keywords: Meta analysis, POE Model, Conceptual Undersatanding

\begin{abstract}
Abstrak: Penelitian ini bertujuan untuk menganalisis model pembelajaran POE terhadap pemahaman konsep fisika. Metode yang digunakan dalam penelitian ini adalah meta analisis. Meta analisis merupakan penelitian yang mengkaji hasil penelitian yang sejenis. Data diperoleh dari dokumendokumen jurnal nasional maupun internasional yang diambil secara purposive sampling berdasarkan kesesuaian dengan tema penelitian. Analisis data menggunakan analisis data kuantitatif dengan presentasen dan analisis data kualitatif berupa deskripsi-deskripsi hasil penelitian yang ditemui. Berdasarkan analisis data ditemukan bahwa model pembelajaran POE dapat meningkatkan pemahaman konsep siswa
\end{abstract}

Kata Kunci: Meta analisis, Model POE, Pemahaman Konsep

\section{PENDAHULUAN}

Pembelajaran saat ini menekankan pada proses ilmiah yang menuntut siswa untuk memahami apa yang dipelajari. Hal ini mengarah kepada pendidik agar memberikan caracara yang inovatif baru dalam pembelajaran untuk meningkatkan pemahaman konsep siswa. Pemahaman adalah tingkat belajar yang lebih tinggi daripada pengetahuan yang diperoleh (sudjana, 2011). Pemahaman diperoleh berdasarkan pengalaman belajar yang dilakukan siswa secara mendiri. Hal ini sesuai dengan pendapat Trianto (2007) bahwa memberi kesempatan kepada siswa untuk menemukan atau menerapkan ide mereka sendiri akan meningkatkan hasil belajar mereka. Dengan menerapkan model pembelajaran yang dapat meningkatkan pemahaman konsep siswa, maka ketercapaian kegiatan belajar mengajar akan tercapai dengan baik.

Model pembelajaran merupakan salah satu perangkat yang digunakan dalam kegiatan pembelajaran untuk mencapai tujuan belajar. Salah satu model pembelajaran yang menekankan pada kegiatan proses yaitu model pembelejaran POE. Model pembelajaran POE memiliki 3 langkah utama yaitu memprediksi (Predict), melakukan observasi (Observe), dan Menjelaskan (Explain). Model pembelajaran POE merupakan model pembelajaran yang dikenalkan oleh White and Guston. Menurut White and Guston, model pembelajaran POE 
dikembangkan untuk mengetahui kemampuan siswa dalam memprediksi suatu permasalahan. Dalam kegiatan memprediksi diharapkan siswa memperoleh konsep yang mereka pelajari.

Selain itu paul Suparno menyatakan bahwa model pembelajaran POE adalah singkatan dari prediction, Observation, dan Explanation. Model Pembelajaran POE menggunakan tiga langkah utama metode ilmiah, pertama adalah prediction yaitu memprediksi, membuat dugaan terhadap suatu peristiwa. Kemudian dalam memprediksi guru menekankan untuk tidak membatasi gagasan dan konsep yang muncul dari pikiran siswa karena semakin banyak dugaan muncul dari pikiran siswa guru dapat mengerti bagaimana konsep serta pengertian siswa tentang persoalan yang diajukan, guru juga dapat mengetahui miskonsepsi terjadi pada pikiran siswa, sehingga ini akan sangat penting untuk guru dapat membuat penjelasan dengan konsep yang benar.

Aktivitas Guru dan Siswa dalam model pembelajaran POE (predict-observe-explain) dapat dilihat pada tabel di bawah ini:

Tabel 1. Aktivitas guru dan siswa dalam model pembelajaran POE

\begin{tabular}{|c|c|c|}
\hline Langkah Pembelajaran & Aktivitas Guru & Aktivitas Siswa \\
\hline $\begin{array}{l}\text { Tahap 1 } \\
\text { Meramalkan (Predict) }\end{array}$ & $\begin{array}{lr}\text { Memberikan } & \text { apersepsi } \\
\text { terkait } & \text { materi } \\
\text { pembelajaran } & \text { yang akan } \\
\text { disampaikan. } & \end{array}$ & $\begin{array}{l}\text { Memberikan prediksi } \\
\text { permasalahan } \\
\text { berdasarkan pengamatan } \\
\text { atau pengalaman pribadi } \\
\text { siswa. }\end{array}$ \\
\hline $\begin{array}{l}\text { Tahap } 2 \\
\text { Mengamati (Observe) }\end{array}$ & $\begin{array}{l}\text { Sebagai fasilitator dan } \\
\text { mediator }\end{array}$ & $\begin{array}{lr}\text { Melakukan } & \text { percobaan } \\
\text { untuk } & \text { membuktikan } \\
\text { prediksi } & \text { atau } \\
\text { permasalahan. } & \end{array}$ \\
\hline $\begin{array}{l}\text { Tahap } 3 \\
\text { Menjelaskan (Explain) }\end{array}$ & $\begin{array}{l}\text { Memfasilitasi } \\
\text { diskusi }\end{array}$ & $\begin{array}{lr}\begin{array}{l}\text { Mendiskusikan } \\
\text { observasi }\end{array} & \begin{array}{r}\text { hasil } \\
\text { dan }\end{array} \\
\text { membandingkan } & \text { dengan } \\
\text { permasalahan } & \text { awal. } \\
\text { Siswa } & \text { secara } \\
\text { berkelompok } & \text { melakukan } \\
\text { presentasi } & \text { untuk } \\
\text { menjelaskan } & \text { hasil } \\
\text { observasi. } & \end{array}$ \\
\hline
\end{tabular}

(Diadaptasi dari Wah Liew, 2004)

Menurut Warsono dan Hariyanto (2012), menjelaskan beberapa manfaat yang diperoleh dari penggunaan model pembelajaran POE adalah sebagai berikut:

a. dapat digunakan untuk menggali gagasan awal yang dimiliki oleh siswa dapat dilihat dari hasil prediksi yang dibuat siswa;

b. memberikan informasi kepada guru tentang pemikiran siswa melalui yang dibuat siswa;

c. membangkitkan diskusi baik antara siswa dengan siswa maupun antara siswa dengan guru;

d. memberikan motivasi kepada siswa untuk menyelidiki konsep yang belum dipahami untuk membuktikan hasil prediksinya;

e. membangkitkan rasa ingin tahu siswa untuk menyelidiki. 
Pemahaman konsep merupakan keadaan siswa mampu mengkonstruksi makna dari pembelajaran yang diajarkan. Siswa dikatakan memahami apabila mereka menghubungkan pengetahuan baru dengan pengetahuan yang lama dan pengetahuan konseptual menjadi dasar dalam memahami (addison Wesley longman). Menurut Anderson dan Krathwohl (2010), terdapat 7 proses kognitif diantaranya yaitu remembering (mengingat), understanding (memahami), applying (menerapkan), analysing (menganalisis), evaluating (mengevaluasi), dan creating (mencipta). Anderson dan Krathwol menjabarkan 7 proses kognitif pemahaman yaitu :

1. Menafsirkan (interpreting),kegiatan ini merupakan siswa mampu mengubah informasi yang diperoleh baik berupa kata-kata, gambar, angka, dan semacamnya.

2. Memberikan contoh (examplifying), proses kognitif mencontohkan menjadi terjadi manakala peserta didik memberikan contoh tentang konsep atau prinsip umum. Mencontohkan melibatkan proses identifikasi ciri-ciri pokok dari konsep atau prinsip umum.

3. Mengklasifikasikan (classifying), proses kognitif mengklasifikasikan terjadi ketika peserta didik mengetahui bahwa misalnya (suatu contoh) yang telah disebutkan termasukdalam kategori tertentu (misalnya, konsep atau prinsip)

4. Meringkas (summarizing), proses kognitig meringkas atau merangkum terjadi ketika peserta didik mengemukakan satu kalimat yang mempresentasikan informasi yang sudah diterimanya

5. Menarik inferensi (infering)

6. Membandingkan (comparing), proses kognitif membandingkan melibatkan proses mendeteksi persamaan atau perbedaan dari dua atau lebih objek, peristiwa, ide, bahkan masalah atau situasi.

7. menjelaskan (explaining). Proses kognitif menjelaskan berlangsung ketika peserta didik mampu membuat model sebab-akibat dalam sebuah sistem.

\section{METODE PENELITIAN}

Metode penelitian yang digunakann adalah meta analisis. Meta analisis merupakan kajian terhadap beberapa dokumen dengan tema penelitian yang sejenis. Teknik pengumpulan data menggunakan teknik dokumentasi dari 20 jurnal nasional maupun jurnal internasional. Instruman penelitian ditentukan oleh peneliti berdasarkan tujuan dari penelitian. Analisis data menggunakan analisis kuantitatif yang berupa prosentase dan analisis kualitatif yang berisi deskripsi atas temuan dalam penelitian.

\section{HASIL DAN PEMBAHASAN}

Dokumen yang diperoleh berupa jurnal nasional dan jurnal internasional tentang pembelajaran menggunakan model POE (Predict, Observe, and Explain) berjumlah 20 dokumen. Meta analisis berdasarkan tujuan penelitian ini yaitu untuk mengetahui pengaruh model pembelajaran POE terhadap pemahaman konsep. Berikut data prosentase hasil analisis yang diperoleh: 


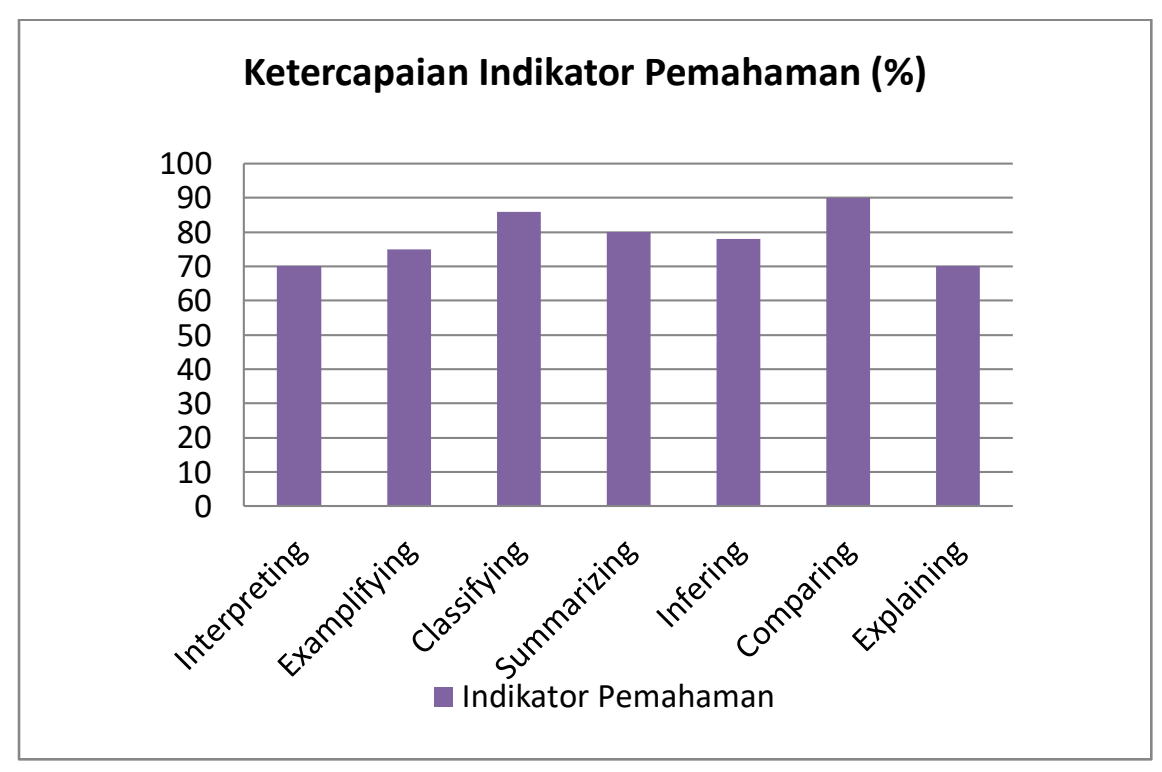

Grafik 1. Ketercapaian Indikator Pemahaman

\section{a. Interpreting}

Pada indikator Interpreting, dari 20 artikel yang telah dikaji menunjukkan ketercapaian yang baik yaitu sebesar $70 \%$. Interpreting merupakan aspek dimana siswa mampu mengubah informasi yang diperoleh baik berupa angka menjadi kata, angka menjadi gambar, dan lainnya. Pada model pembelajaran POE dalam kegiatan observasi siswa dituntut untuk mengolah data. Data tersebut kemudian menjadi acuan dari hasil observasi siswa yang kemudian di integrasikan menjadi kesimpulan. Dari Hasil kesimpulan tersebut jika siswa mengalami kesalahan konsep maka guru akan menyampaikan konsep yang benar. Hal ini akan memperkuat pemahaman konsep mereka.

b. Memberikan contoh (examplifying),

Pada indikator examplifying, dari 20 artikel yang telah dikaji menunjukkan ketercapaian yang baik yaitu sebesar $75 \%$. Examplifying merupakan aspek dimana siswa mampu memberikan contoh terkait dengan konsep yang dipelajari. Pada model pembelajaran POE hal ini ditekankan pada langkah prediksi. Prediksi merupakan dugaan awal siswa berdasarkan permasalahan yang disajikan. Selain menduga, siswa diberi kesempatan untuk memberikan contoh lain yang terkait dengan permasalahan tersebut.

c. Mengklasifikasikan (classifying),

Pada indikator Classifying, dari 20 artikel yang telah dikaji menunjukkan ketercapaian yang baik yaitu sebesar $86 \%$. Classifying merupakan aspek siswa mampu mengklasifikasi permasalahan berdasarkan konsep. Mengklasifikasi ditekankan pada kemandirian siswa dalam menjawab suatu topik atau konsep tertentu. Pada model pembelajaran POE, mengklasifikasi dapat di munculkan dari langkah explain (menjelaskan). Pada kegiatan ini siswa dituntut agar mampu menjelaskan konsep yang telah diklasifikasi sesuai dengan permasalaham atau tema.

d. Meringkas (summarizing),

Pada indikator summarizing, dari 20 artikel yang telah dikaji menunjukkan ketercapaian yang baik yaitu sebesar $80 \%$. Proses kognitif meringkas atau merangkum terjadi ketika peserta didik mengemukakan satu kalimat yang mempresentasikan informasi yang sudah diterimanya. Pada model pembelajaran POE hal ini terjadi ketika siswa 
mempresentasikan hasil diskusi yang telah diperoleh berdasarkan data-data observasi yang telah dilakukan. Proses menyampaikan informasi ini merupakan suatu kelebihan daripada model pembelajaran POE. Siswa akan memahami sesuatu yang akan mereka informasikan dengan cara mereka sendiri.

e. Menarik inferensi (infering)

Pada indikator infering, dari 20 artikel yang telah dikaji menunjukkan ketercapaian yang baik yaitu sebesar 78\%. Menarik inferensi (infering) merupakan aspek siswa dalam menarik kesimpulan hasil percobaan. Jika siswa mengalami kesalahan dalam menarik kesimpulan, maka guru akan memberikan penjelasan mengenai konsep yang benar. Sehingga siswa mampu menganalisis kesalahan yang mereka alami. Namun jika siswa dapat menjelaskan konsep dengan benar, maka siswa akan lebih memahami karena adanya penjelasan dari guru.

f. Membandingkan (comparing),

Pada indikator comparing dari 20 artikel yang telah dikaji menunjukkan ketercapaian yang baik yaitu sebesar $90 \%$. Proses kognitif membandingkan melibatkan proses mendeteksi persamaan atau perbedaan dari dua atau lebih objek, peristiwa, ide, bahkan masalah atau situasi. Pada model pembelajaran POE, hal ini ditekankan pada proses prediksi, observasi, dan menjelaskan. Membandingkan merupakan aspek yang paling penting dalam pemahaman. Siswa dikatakan memahami konsep, ketika mereka dapat membandingkan konsep yang benar maupun salah.

g. Menjelaskan (explaining).

Pada indikator explaining, dari 20 artikel yang telah dikaji menunjukkan ketercapaian yang baik yaitu sebesar 70\%. Menjelaskan (explaining) merupakan suatu aspek siswa menyampaikan informasi berdasarkan hasil observasi. Kegiatan ini merupakan timbal balik dari seluruh kegiatan pemahaman konsep. Pada kegiatan ini selain siswa dituntut untuk memahami konsep, siswa juga harus dapat menyampaikan konsep dengan baik dan benar.

Berdasarkan hasil penelitian, model pembelajaran POE dapat meningkatkan pemahaman konsep. Beberapa aspek pemahaman yang telah diuraikan diatas merupakan acuan dari peneliti untuk mengetahui pengaruh model pembelajaran POE dalam meningkatkan pemahaman konsep. Model pembelajaran POE merupakan model pembelajaran yang menekankan proses kepada siswa untuk menemukan konsep yang dipelajari berdasarkan hasil observasi. Model Pembelajaran POE berkaitan dengan aspek-aspek pada pemahaman. Hal ini dapat ditunjukkan dari hasil kajian peneliti dari beberapa jurnal nasional maupun internasional yang telah dikaji. Semua aspek pemahaman dapat diperoleh dari kegiatan-kegiatan pembelajaran menggunakan model pembelajaran POE. Penelitian ini dibatasi dengan hanya mengkaji 20 artikel. Namun untuk selanjutnya disarankan untuk mengkaji lebih banyak jurnal untuk memperoleh hasil yang lebih baik.

\section{KESIMPULAN}

Berdasarkan analisis data secara kuantitatif yang berupa prosentase dan analisis data secara kualitatif yang berupa deskripsi. Peneliti menyimpulkan bahwa model pembelajaran POE (Predict, Observe, And Explain) dapat meningkatkan pemahaman. Beberapa indikator pemahaman dapat ditekankan pada langkah model pembelajaran POE. Ketercapaian indikator pemahaman merupakan bagian dari kegiatan model pembelajaran POE. Konsep yasng dipelajari siswa akan menjadi lebih baik ketika siswa dituntut untuk menemukan konsep yang mereka pelajari. 


\section{SARAN}

Pada meta analisis semakin banyak jurnal yang dikaji maka akan semakin valid hasil penelitian yang diperoleh. Saran untuk kedepannya yaitu menambah jurnal baik nasional maupun internasional yang berkaitan dengan model pembelajaran POE dalam meningkatkan pemahaman konsep.

\section{DAFTAR PUSTAKA}

Anderson, Lorin W, dan David R. Krathwohl. 2010. Pembelajaran, Pengajaran, dan Asesmen. Yogyakarta: Pustaka Pelajar.

Bundu, Patta. 2006. Penilaian Keterampilan Proses dan Sikap Ilmiah dalam Pembelajaran Sains. Jakarta: Depdiknas Pendidikan Tinggi dan Ketenagaan.

Liew, C.W. 2004. The Effectiveness of Predict, Observe, Explain Technique in Diagnosing Studens' Understanding of Science and Identifying Their Level of Achievement.

Joyce, B. dan Marsha Weil. 2009. Model of Teaching Model Model Pengajaran. (Terj.) Achmad Fawaid dan Ateilla Mirza. Yogyakarta: Pustaka Pelajar.

Kementerian Pendidikan dan Kebudayaan RI. 2014. Buku Guru: Ilmu Pengetahuan Alam untuk SMP/MTs Kelas VIII. Jakarta: Kementerian Pendidikan dan Kebudayaan Republik Indonesia.

Liang, J.C. 2011. "Using POE to Promote Young Children's Understanding of the Properties of Air", Asia-Pasifik Journal of Rereach in Early Childhood Education, Vol. 5, No. 1.

Memes, Wayan. 2000. Model Pembelajaran Fisika di SMP. Jakarta: Proyek Pemgembangan Guru sekolah Menengah.

Permatasari, Obimita Ika. 2011. "Keefektifan Model Pembelajaran Predict-Observe- Explain (POE) Berbasis Kontekstual dalam Peningkatan Aktivitas dan Hasil Belajar Siswa SMP Kelas VII pada Pokok Bahasan Tekanan”. Skripsi UNNES Semarang.

Sardiman, A.M. 2014. Interaksi dan Motivasi Belajar Mengajar. Jakarta: Rajawali Press.

Sari, Kurnia Novita. 2014. "Keefektifan Model Pembelajaran POE (Predict- ObserveExplain) terhadap Aktivitas dan Hasil Belajar IPA Materi Perubahan Sifat Benda pada Siswa Kelas V SD Negeri Kejambon 4 Kota Tegal”. Skripsi UNNES Semarang.

Sudjana, Nana. 2012. Penilain Hasil Proses Belajar Mengajar. Bandung: Remaja Rosdakarya.

Suparno, Paul. 2007. Metodologi Pembelajaran Fisika Kontruktivistik \& Menyenangkan. Yogyakarta: Universitas Sanata Dharma Yogyakarta.

Teerasong, S., et.al. 2007. "Development of a Predict-Observe-Explain Strategi for Teaching Flow Injektion an Undegraduate Chemistry" The Internasioal Journal of Learning, Vol. 17, No. 3.

Warsono dan Hariyanto. 2012. Pembelajaran Aktif Teori dan Assesmen. Bandung: Remaja Rosdakarya.

White dan Gunstone. 1992. Probing Understanding. Hongkong: Graficraft Typosetters Ltd.

Wu, Y.T. dan C.C. Tsai. 2005. "Effects of Constructivistoriented Instruction on Elementary School Students' Cognitive Structures", Jornal of Biological Education, Vol. 39, No. 3.

Yupani, Garminah, dan Mahadewi. 2013. "Pengaruh Model Pembelajaran Predict-ObserveExplain (POE) Berbantuan Materi Bermuatan Kearifan Lokal terhadap Hasil Belajar IPA Siswa Kelas IV". Laporan Penelitian Universitas Pendidikan Ganesha.Volume 5, Nomor 1, Juni 20179 